\title{
Assessment of Community Psycho-behavioral Responses during the outbreak of novel coronavirus (2019-nCoV): A cross sectional study
}

Doaa Mohamed Magdy ( $\sim$ doaamagdy_2020@yahoo.com )

Assuit university, https://orcid.org/0000-0003-2807-9542

Ahmed Metwally

Chest departement, Assuit university hospital

Omar Magdy

Medical student, Assuit university hospital

\section{Research}

Keywords: Anxiety; coronavirus; precaution; psychological impact.

Posted Date: April 29th, 2020

DOI: https://doi.org/10.21203/rs.3.rs-25146/v1

License: (1) This work is licensed under a Creative Commons Attribution 4.0 International License.

Read Full License

Version of Record: A version of this preprint was published at AIMS Public Health on January 1st, 2021. See the published version at https://doi.org/10.3934/publichealth.2022003. 


\section{Abstract}

Background: The novel coronavirus 2019 (2019-nCoV) is a public health emergency of international concern resulting in adverse psychological impacts during the epidemic.

The aim of this study: To examine the public's knowledge and psychological impact during the outbreak of (2019-nCoV) and the extent to which various precautionary measures have been adopted.

Materials \& Methods: From 1 to 10 April 2020, we conducted an online survey. The online survey collected information on demographic data, precautionary measures against (2019-nCoV), self-health evaluation, knowledge and concerns about (2019-nCoV) and appraisal of crisis management. Psychological impact was assessed by General Anxiety Disorder 7-item (GAD-7) scale. The designed questionnaire was answered by participants, and the collected data were statistically analyzed.

Results: This study included 1200 respondents. In total, $80 \%$ of respondents rated the psychological impact; $18 \%$ reported minimal anxiety; $34 \%$ reported mild anxiety and (48\%) with moderate anxiety symptoms. A large proportion (74\%) believed that they were very or somewhat likely to contract (2019nCoV) while only $35 \%$ believed they were unlikely to survive if they contracted the disease. (58\%) of the respondents, practiced the precautionary measures directed against person to person droplet spread.

Respondents with moderate level of anxiety were most likely to take comprehensive precautionary measures against the infection. In addition, older, female, more educated people as well as those who are more likely to contract infection.

Conclusions: During the outbreak, more than half of the respondents rated the psychological impact as moderate anxiety. Thus, the psychological needs during the outbreak should be addressed appropriately. Our results highlight the need to promote protective personal health practices to interrupt the transmission of the (2019-nCoV) in the community must take into account. Therefore, educational public programs about preventive measures should be targeted at the identified groups with low current uptake of precautions.

\section{Introduction}

The novel coronavirus disease 2019 (2019-nCoV) is a global health crisis, and is by far the largest outbreak of atypical pneumonia since the severe acute respiratory syndrome (SARS) epidemic in 2003 [1]. (2019-nCoV) was first identified in December 2019 in China and had spread to 13 countries by January 24,2020 [2].

The (2019-nCoV) as an emerging infectious disease threatens not only life but also the psychological health. Outbreaks can put significant psychological stress and anxiety among people, especially in the affected countries, and the media have huge impacts on increasing mental distress $[3,4]$. Since the outbreak and its spread, measures by the government have been swift; to slow the spread of 
transmission, complete quarantine was extended to several provinces and cities. The ongoing (2019$\mathrm{nCoV}$ ) epidemic is inducing anxiety, there has been fear of suffering from the disease or losing loved ones, rapid changes in the way of life (e.g., study, work, social gatherings), and disrupted plans due to travel restrictions and social distancing. Though, these experiences are all important to recognize the seriousness of the public health challenge facing our community $[5,6]$.

Therefore, the purpose of this study, to examine four areas of public reaction to the (2019-nCoV) outbreak: preventive practices, perception of self-health, knowledge of (2019-nCoV), and appraisal of (2019-nCoV) crisis management.

\section{Materials And Methods}

\section{Study design and subjects' selection}

We modified and expanded a specially-designed questionnaire provided by researchers from Chest Department, Assuit University hospital. This survey was conducted by sending electronic questionnaire to minimize personal contact during the outbreak between 1st April and 12th April, 2020.

Sampling was done by sending the electronic surveys to a representative stratified random sample of 1500 adults at Assuit governate, Egypt. The study was approved by the Faculty of Medicine Ethics Committee, Assiut University. The objectives of the study were explained to subjects before enrollment. Their voluntary participation was documented with their written consent on the first page of the questionnaire. Data collection took place over two weeks during the outbreak of (2019-nCoV).

\section{Data Collection:}

The questionnaire used was partially adapted from previously published studies $[7,8]$. The authors included additional questions related to the (2019-nCoV) outbreak.

The structured questionnaire considered the following questions: (1) demographic data; (2) precautionary measures against (2019-nCoV) in the past 14 days; (3) self-health evaluation and the psychological impact during (2019-nCoV) outbreak; (4) knowledge and concerns about (2019-nCoV); and (5) appraisal of crisis management.

Basic demographic questions included age, gender, education level, marital and employment status.

\section{I-Preventive Measures}

The first part of the survey, we addressed the precautionary measures against (2019-nCoV) in the past 2 weeks before the interview based on a scale from 1 (Always) to 5 (Don't know). This part discussed 
washing hands, covering mouth when sneezing or coughing, using soap or disinfectants, wearing mask in public areas, using serving utensils for shared food, avoiding public places (e.g. restaurants), and washing hands after touching objects.

We constructed a composite index indicating the total number (from 0 to 8 ) of preventive measures taken. A dichotomous indicator of preventive behavior was calculated based on the mean number of precautions taken (4.65): "low" (<5) versus "high" (>6).

\section{II- Self-Health Perception}

The next part of the survey composed of 3 sets dealt with the respondents' perception of their own health.

The first set covered seven physical health complaints over the previous 2 weeks. We created a composite index of symptoms by adding all instances of health complaints.

The second set of survey assessed level of anxiety using General Anxiety Disorder 7-item (GAD-7) scale [9]. It is a 7 item questionnaire was developed that asked patients how often, during the last 2 weeks, they were bothered by each symptom. Response options were "not at all," "several days," "more than half the days," and "nearly every day," scored as $0,1,2$, and 3 , respectively. The total anxiety score was divided into $(0-4)=$ minimal anxiety, $(5-9)=$ mild anxiety, $(10-14)=$ moderate anxiety, and $>14=$ severe anxiety). The scale had an Alpha reliability coefficient of 0.824 .

The third set addressed respondents' risk perception in terms of their likelihood of contracting (2019$\mathrm{nCoV}$ ) and survival if diagnosed with the disease. Scores were 4 (very likely) to 0 (don't know). On the basis of the average score (3.4; standard deviation [SD] 0.11), we created a dichotomous variable to contrast respondents who believed they were susceptible to contracting (2019-nCoV) (scores 3 and 4) with those who did not (scores $0-2$ ).

\section{Knowledge of (2019-nCoV):}

We also administered basic questions on (2019-nCoV) mode of transmission. Responses were scored 0 (incorrect) or 1 (correct); a composite index indicated the number of correct answers, from none correct (0) to all three correct (3).

In addition, we asked about various sources of this information; Internet; social media as Facebook and Whats app, WHO web sites, official statements by radio and television, family member, or others.

\section{IV-Appraisal of Crisis Management:}

We addressed respondents' appraisal of crisis management. Five questions carried out (Alpha reliability 0.813 ) to assess opinions on information distribution. Scores were 1 (very negative) to 6 (very positive). 
On the basis of the mean score (4.83; SD 0.617), we calculated a dichotomous index: negative appraisal (scores $<4.7$ ) versus positive appraisal (scores $>4.8$ ).

Finally, we evaluated the public's acceptance of quarantine regulations. The scores were dichotomized into "agreement" (1) versus "no agreement" and "don't know" (2).

\section{Statistical analysis:}

All statistical analyses were conducted using SPSS, version 21 (IBM Inc., Armonk, NY, USA). Quantitative measurement was expressed by medians and qualitative variables were presented as absolute frequency and percentage. Factor analysis examined trends among four factors ((nCoV-2019) prevention, perception of self-health, knowledge of (nCoV-2019), and perception of health authorities' crisis management). Logistic regression was used to calculate the odds ratio (OR) with a $95 \%$ confidence interval in order to identify predictors for greater adoption of the recommended precautionary measures (defined as at least five of the eight specified strategies). $P$ values of less than 0.05 were regarded as statistically significant.

\section{Results}

We received responses from 1500 respondents. Out of them, $1200(80 \%)$ respondents completed the survey, 200 (13.3\%) did not complete the survey, and another 100 (6.7\%) did not respond.

Sociodemographic characteristics of the study population are presented in Table 1 . The majority of respondents were women (68\%), Respondents were classified into five age categories: 18-24 (28\%), 25$34(52 \%), 35-44(8 \%), 45-59$ (6\%), 60 years and above (6\%). Overall, $64 \%$ were married, and $42 \%$ had at least 1 child. In total, $13.7 \%$ had no educational qualifications, $53.3 \%$ had high school diplomas, and $33 \%$ had university degrees.

Figure (1) displays the respective proportions of respondents who reported practicing each of specified precautionary measures as recommended to prevent the transmission and contracting of (2019-nCoV). It was observed that recommended preventive measures were not practiced uniformly. The most practiced measures in the last 2 weeks before the interview were using soap and disinfectants when washing hands (85\%) and washing hands after sneezing, coughing, or clearing the nose $(75 \%)$. The least practiced measure was wearing a mask over the mouth in public areas. A total of $20 \%$ wears masks, and most did so only when visiting a clinic or hospital or when the mask was part of a uniform (as in healthcare workers). Lastly, (58\%) of the respondents practiced at least five of the eight specified preventive strategies to improve personal hygiene Table (2).

Respondents' perception of their health was generally positive. We reported the mean number of health complaints in our sample was 0.46 (SD 0.81). A relatively lower proportion of respondents $(22.4 \%)$ reported having any of our seven physical health complaints over the previous 2 weeks. 
It was observed that mean anxiety score was 7.43 (SD 3.18). The survey showed moderate anxiety level among respondent; only $18 \%$ of respondents reported minimal anxiety. Most respondents $(74 \%)$ believed that they were "very likely" or "somewhat likely" to contract (2019-nCoV) during the current outbreak. Those who thought they were likely to get the disease reported slightly more anxiety. Regarding the likelihood of surviving if they contracted the disease, $10 \%$ believed they were unlikely (6\%"not very likely" and $4 \%$ "not likely at all") to survive but (25\%) were uncertain about this.

Figure (2): shows the percentages of the GAD-7 anxiety levels category among surveyed respondents. Out of the 1200 respondents, 216 (18\%) reported minimal anxiety, 408 (34\%) reported mild anxiety, 576 (48\%) reported moderate anxiety, and none of them reported severe anxiety.

Regarding knowledge of (2019-nCoV), the sample correctly answered an average of 1.72 (SD 0.92) of 3 questions on (2019-nCoV) transmission. Approximately $63 \%$ answered two or more questions correctly; $11.7 \%$ did not answer any questions correctly.

Figure (3): shows the percentages of different information resources among respondents.

Internet and social networks, mainly Facebook and WhatsApp were the most common source of information (73.2\%) followed by official statements or press releases by radio and television from MOHP (24.5). While, family member and other resources were (2.3\%).

Respondents had a generally high opinion of authorities' crisis management. More than $80 \%$ thought official information was accurate, clear, sufficient, timely, and trustworthy, and $68 \%$ were prepared to accept 14-day quarantine, even in the absence of symptoms or non -close contact with the (2019-nCoV) infected patient.

Table (3) demonstrates predictors for the adoption of precautionary measures among study population. It was noted that respondents who had a moderate level of anxiety were most likely to adopt more precautionary measures against (2019-nCoV). Women were more likely to adopt comprehensive precautionary measures against (2019-nCoV) (OR 0.77; 95\% Cl 0.65 to 0.85). Respondent $>35$ years of age were more inclined to take preventive measures (OR $0.87 ; 95 \% \mathrm{Cl} 0.80$ to 0.94 ) than their younger counterparts (OR 1.36; $95 \% \mathrm{Cl} 1.12$ to 1.65$)$. There was a strong positive dose-response gradient with increasing level of educational attainment ( $p$ for linear trend were, 0.05 and 0.01 respectively). Risk perception in terms of a higher self-perceived likelihood of contracting (2019-nCoV) was also a significant positive predictor for adaption of preventive measure (OR 1.93; $95 \% \mathrm{Cl} 1.63$ to 2.11 ).

\section{Discussion}

The (2019-nCoV) outbreak constitutes one of the most challenging threats to national and international public health concern. The epidemic had a significant impact on psychological healthcare communities. Therefore, we examined public reaction to the (2019-nCoV) outbreak: preventive practices, perception of self-health, knowledge of (2019-nCoV), and appraisal of crisis management. 
We reported that more than half of the respondents follow infection control protocols; washed their hands with soaps after touching contaminated objects, covered their mouth when coughing or sneezing, and wore masks. The experiences of the 2003 SARS-CoV epidemic could have changed the perception of the general public towards precautionary measures and have led to a positive effect by giving respondents the sense of confidence in prevention control measures [10].

In this study, the respondents rated their psychological impact during the outbreak; (48\%) of them reported moderate anxiety symptoms. In accordance, Wang et al. [11] evaluated psychological impacts, depression, stress, and anxiety at the beginning of the (2019-nCoV) outbreak as measured by the DASS21. The authors revealed that $53.8 \%$ experienced severe psychological impacts. Moreover, $16.5 \%, 28.8 \%$, and $8.1 \%$ of the respondents reported moderate to severe levels of depression, anxiety, and stress [11]. Also, Xu et al. demonstrated that anxiety and fear were very prevalent among patients with (2019-nCoV) [12]. In another cross sectional study, Al-Rabiaah et al. studied the impacts of the Middle East respiratory syndrome coronavirus (MERS-CoV) epidemic on medical students' perception and found that all of these students experienced stress [13].

We found that anxiety appeared to motivate preventive behavior; those people with moderate level of anxiety were most likely to take comprehensive precautionary measures against the infection. The outbreak itself and the control measures may lead to widespread fear and panic, especially stigmatization and social isolation of confirmed patients, survivors and relations, whom may escalate into further negative psychological reactions.

Our sample revealed that internet (73.2\%) was the most common source of primary health information for the general public during (2019-nCoV) epidemic, followed by official health authority statements through television. Despite, the perceived availability of resources of information was not found to affect knowledge and only $20.7 \%$ of respondents were able to correctly answer all three questions. The results revealed that there were no correlation between the public's knowledge about (2019-nCoV) and adoption of precautionary measures to prevent the spread of infection. These findings confirm that knowledge of a disease is not sufficient to trigger preventive action.

As the (2019-nCoV) epidemic continues to spread, healthcare professional were uncertain how to control the epidemic. Consequently, on assessing public opinion of authorities' crisis management in our survey in Egypt was highly positive and distinctive. However, the quality of official information of dissemination and acceptance of quarantine regulations wasn't correlated with taking preventive measures. This may be related to their high positive rating.

Our findings revealed that, older, women and more educated people brought about the greatest uptake of preventive measures. In a study by Wong et al. about MERS-CoV outbreak perceptions of risk and stress evaluation among health care personnel; females were found to have significantly more fear of contracting the infection compared to males in terms of personal protection and social avoidance [14]. In another study, undergraduate female students reported more worries and exaggerated responses [15]. 
As anticipated, younger, less educated males were least likely to adopt appropriate preventive measures in protecting themselves. This underlines the importance of health promotion messages for an attempt to raise the level of protective precautions undertaken by this vulnerable subgroup.

\section{Conclusion}

In this survey study, $48 \%$ of respondent reported moderate anxiety symptoms. We found that those people with moderate level of anxiety as well as older, women and more educated were most likely to take comprehensive precautionary measures against the infection. Whereas, those risk taking individuals e.g. young males may require adjustment of their attitude in order to optimize self-protection measures against (2019-nCoV) infection and community spread. Therefore, we recommend health promotion campaigns and communication techniques to be developed and rigorously evaluated their effectiveness for public health.

\section{Declarations}

\section{Ethical approval and consent to participate}

The research received ethical approval from the Ethics Committee of the Faculty of Medicine. The data were confidential. All procedures in the current study were performed according to the ethical standards of the institutional research committee.

\section{Consent for publication}

Not applicable.

\section{Institutional review board statement}

This study was approved by the Faculty of Medicine Ethics and Scientific Research Committees.

\section{Availability of data and materials}

The datasets used and analyzed during the current study are available from the corresponding author on reasonable request.

\section{Declaration of Competing Interest}

The authors have no conflicts of interest to declare.

\section{Funding}

This research did not receive any specific grant from funding agencies in the public, commercial, or notfor-profit sectors. 


\section{Authors' contributions}

Conceptualization and methodology: Doaa M Magdy, Ahmed Metwally and Omar Magdy; validation, formal analysis, writing and editing: Doaa M Magdy, Ahmed Metwally. All authors have read and agreed to the published version of the manuscript

\section{Acknowledgments}

We express our appreciation to all interviewers for conducting this survey.

\section{References}

1. 1.Al-Hazmi A. Challenges presented by MERS corona virus, and SARS corona virus to global health. Saudi J Biol Sci. 2016;23(4):507-11. doi: 10.1016/j.sjbs.2016.02.019. [PubMed: 27298584]. [PubMed Central: PMC4890194].

2. Nishiura H, Jung SM, Linton NM, Kinoshita R, Yang Y, Hayashi K, et al. The extent of transmission of novel coronavirus in Wuhan, China, 2020. J Clin Med. 2020;9(2). doi: 10.3390/jcm9020330. [PubMed: 31991628]. [PubMed Central: PMC7073674].

3. Yang HY, Duan GC. [Analysis on the epidemic factors for the corona virus disease]. Zhonghua Yu Fang Yi Xue Za Zhi. 2020;54(0). Chinese. E021. doi: 10.3760/cma.j.cn112150-20200227-00196. [PubMed: 32125129].

4. Paules $\mathrm{Cl}$, Marston HD, Fauci AS. Coronavirus infections-more than just the common cold. JAMA. 2020. doi: 10.1001/jama.2020.0757. [PubMed: 31971553].

5. Hawryluck L, Gold WL, Robinson S, Pogorski S, Galea S, Styra R. SARS control and psychological effects of quarantine, Toronto, Canada. Emerg Infect Dis. 2004;10(7):1206-12. doi: 10.3201/eid1007.030703. [PubMed: 15324539]. [PubMed Central: PMC3323345].

6. .Rubin GJ, Wessely S. The psychological effects of quarantining a city. BMJ. 2020;368:m313. doi: 10.1136/bmj.m313. [PubMed: 31992552].

7. Rubin, G.J.; Potts, H.W.W.; Michie, S. The impact of communications about swine flu (influenza A H1N1v) on public responses to the outbreak: Results from 36 national telephone surveys in the UK. Health Technol.Assess. 2010, 14, 183-266.

8. Leung, G.M. Community psycho-behavioural surveillance and related impact on outbreak control in Hong Kong and Singapore during the SARS epidemic. Hong Kong Med. J. 2009, 15 (Suppl. S9), 3034.

9. Spitzer RL, Kroenke K, Williams JB, Lowe B. A brief measure for assessing gen-eralized anxiety disorder: the GAD-7. Arch Intern Med 2006;166(10):1092-7.Epub 2006/05/24.

10. Leung, G.M. The impact of community psychological responses on outbreak control for severe acute respiratory syndrome in Hong Kong. J. Epidemiol. Community Health 2003, 57, 857-863. [CrossRef] [PubMed] 
11. Wang C, Pan R, Wan X, Tan Y, Xu L, Ho CS, et al. Immediate psychological responses and associated factors during the initial stage of the 2019 coronavirus disease (COVID-19) Epidemic among the general population in China. Int J Environ Res Public Health. 2020;17(5).

doi: 10.3390/ijerph17051729. [PubMed: 32155789]. [PubMed Central: PMC7084952].

12. Xu K, Cai H, Shen Y, Ni Q, Chen Y, Hu S, et al. [Management of corona virus disease-19 (COVID-19): The Zhejiang experience]. Zhejiang Da Xue Xue Bao Yi Xue Ban. 2020;49(1). [PubMed: 32096367].

13. Al-Rabiaah A, Temsah MH, Al-Eyadhy AA, Hasan GM, Al-Zamil F, Al-Subaie S, et al. Middle East respiratory syndrome-corona virus (MERS-CoV) associated stress among medical students at a university teaching hospital in Saudi Arabia. J Infect Public Health. 2020. doi: 10.1016/j.jiph.2020.01.005. [PubMed: 32001194].

14. Wong JG, Cheung EP, Cheung V, Cheung C, Chan MT, Chua SE, et al. Psychological responses to the SARS outbreak in healthcare students in Hong Kong. Med Teach2004;26(7):657-9, http://dx.doi.org/10.1080/01421590400006572.

15. Bergeron SL, Sanchez AL. Media effects on students during SARS out-break. Emerg Infect Dis 2005;11(5):732-4, http://dx.doi.org/10.3201/eid1105.040512.

\section{Tables}

Table (1): Demographic characteristics of study population:

\begin{tabular}{|c|c|}
\hline Sociodemographic & $\begin{array}{c}\text { Number of respondent } \\
(\%) \mathrm{N}\end{array}$ \\
\hline \multicolumn{2}{|l|}{ Gender } \\
\hline Men & $(32 \%) 384$ \\
\hline Women & $(68 \%) 816$ \\
\hline \multicolumn{2}{|r|}{ Age in years } \\
\hline $18-24$ & $(28 \%) 336$ \\
\hline $25-34$ & $(52 \%) 624$ \\
\hline $35-44$ & $(8 \%) 96$ \\
\hline $45-59$ & $(6 \%) 72$ \\
\hline $60<$ & $(6 \%) 72$ \\
\hline \multicolumn{2}{|r|}{ Marital status } \\
\hline Single & $(30 \%) 360$ \\
\hline Married & $(64 \%) 768$ \\
\hline Divorced/Separated & $(6 \%) 72$ \\
\hline \multicolumn{2}{|l|}{ Educational level } \\
\hline High school diplomas & $(53.3 \%) 640$ \\
\hline .University degrees & $(33 \%) 396$ \\
\hline No educational qualifications & $(13.7 \%) 164$ \\
\hline \multicolumn{2}{|l|}{ Employment status } \\
\hline Unemployed & $(5.2 \%) 62$ \\
\hline Farmers & $(1.7 \%) 20$ \\
\hline Retired & $(0.5 \%) 6$ \\
\hline Student & $(51.7 \%) 620$ \\
\hline Employed & (41\%)492 \\
\hline
\end{tabular}


Table (2): Variables used in analysis of public reaction during (2019-nCoV) outbreak. 
.Practicing each of eight measures during the past 14 days

Cover mouth with tissue when sneezing or coughing

Cover mouth with bare hand when sneezing or coughing

Wash hands after sneezing, coughing, or clearing nose Use soap or disinfectants when washing hands

Wear mask in public areas

Use serving utensils for shared food

(Avoid public places (e.g. restaurants

Wash hands after touching objects

\begin{tabular}{|c|c|c|c|}
\hline$\%$ & Mean & SD \\
\hline & 4.65 & 1.62 \\
\hline & & \\
\hline 75 & & \\
\hline 60 & & \\
\hline 75 & & \\
\hline 85 & & \\
\hline 20 & & \\
\hline 30 & & \\
\hline 68 & & \\
\hline 45 & & \\
\hline
\end{tabular}

(Preventive measures taken over past 3 days (score 0-8

\section{II-Symptoms (0-7) over past 2 weeks} or fewer of the eight measures 5 or more of the eight measures 6

None

One or more

Anxiety level

Minimal (0-4)

Mild anxiety (5-9)

Moderate anxiety (10-14)

Perceived likelihood of contracting (2019-nCoV)

Very likely (4)

Likely (3)

Not very likely (2)

Not likely at all (1)

Don't know (0)

Likelihood of surviving if infected

Very likely (4)

Likely (3)

Not very likely (2)

Not likely at all (1)

Don't know (0)

Knowledge of (2019-nCoV)

No knowledge (0 of 3 answers correct) (0)

1 of 3 answers correct (1)

2 of 3 answers correct (2)

3 of 3 answers correct (3)

Appraisal of crisis management

"Strongly agree" and "Agree" that information by health authorities is:

Accurate

Clear

Sufficient

Timely

Trustworthy

Agreeable to 14-day quarantine after non close contact with (2019-nCoV) infected person and no symptoms

Agree

Don't agree

\begin{tabular}{|c|c|c|}
\hline 58 & & \\
\hline 42 & & \\
\hline & 0.46 & 0.81 \\
\hline 77.6 & & \\
\hline 22.4 & & \\
\hline & 7.43 & 3.18 \\
\hline 18 & & \\
\hline 34 & & \\
\hline 48 & & \\
\hline & 3.43 & 0.11 \\
\hline 44 & & \\
\hline 30 & & \\
\hline 20 & & \\
\hline 3 & & \\
\hline 3 & & \\
\hline & 2.41 & 0.13 \\
\hline 30 & & \\
\hline 35 & & \\
\hline 6 & & \\
\hline 4 & & \\
\hline 25 & & \\
\hline & 1.72 & 0.92 \\
\hline 11.7 & & \\
\hline 25.0 & & \\
\hline 42.5 & & \\
\hline 20.7 & & \\
\hline & 4.73 & 0.61 \\
\hline 82.2 & & \\
\hline 86.3 & & \\
\hline 84.5 & & \\
\hline 84.4 & & \\
\hline 87.8 & & \\
\hline & 2.1 & 0.12 \\
\hline 68 & & \\
\hline 24 & & \\
\hline & & \\
\hline
\end{tabular}


Table (3):Predictors for greater adoption of precautionary measures against (2019-nCoV) in the previous two weeks 


\begin{tabular}{|c|c|c|}
\hline & $\begin{array}{l}\text { Adjusted } \\
\text { OR }\end{array}$ & $95 \% \mathrm{CI}$ \\
\hline Anxiety level & & \\
\hline Minimal or Mild (score < 7.4 ) & 1.14 & $\begin{array}{c}\text { to } 1.03 \\
1.19 \\
\end{array}$ \\
\hline Moderate or severe $($ score $>7.4$ ) & $2.86^{* *}$ & $\begin{array}{c}1.76 \text { to } \\
2.96\end{array}$ \\
\hline :Gender & & \\
\hline Men & 1.33 & $\begin{array}{l}1.16 \\
\text { to1.52 }\end{array}$ \\
\hline Women & $* * 0.77$ & $\begin{array}{r}\text { to } 0.65 \\
0.85 \\
\end{array}$ \\
\hline \multicolumn{3}{|l|}{ Age in years } \\
\hline$<35$ & 1.36 & $\begin{array}{l}1.12 \text { to } \\
1.65\end{array}$ \\
\hline $35<$ & $* * 0.87$ & $\begin{array}{r}\text { to } 0.80 \\
0.94\end{array}$ \\
\hline Educational level & & \\
\hline High school diplomas & $1.28 *$ & $\begin{array}{l}0.86 \\
\text { to1.46 }\end{array}$ \\
\hline .University degrees & $* * 1.14$ & $\begin{array}{r}\text { to } 0.92 \\
1.32\end{array}$ \\
\hline No educational qualifications & 0.90 & $\begin{array}{r}\text { to } 0.72 \\
1.00\end{array}$ \\
\hline Personal health evaluation & & \\
\hline Symptoms over past 2 weeks & & \\
\hline None & 1.01 & $\begin{array}{c}0.94 \text { to } \\
1.08\end{array}$ \\
\hline One or more & 0.96 & $\begin{array}{c}\text { to } 0.74 \\
1.20\end{array}$ \\
\hline \multicolumn{3}{|l|}{ Perceived likelihood of (2019-nCoV) } \\
\hline Not likely & 1.03 & $\begin{array}{c}0.97 \text { to } \\
1.08\end{array}$ \\
\hline Likely & $1.93^{* *}$ & $\begin{array}{c}\text { to } 1.63 \\
2.11\end{array}$ \\
\hline \multicolumn{3}{|l|}{ Knowledge of (2019-nCoV) } \\
\hline Two or fewer correct answers & 1.01 & $\begin{array}{l}0.93 \text { to } \\
1.07\end{array}$ \\
\hline Three correct answers & 0.94 & $\begin{array}{r}\text { to } 0.75 \\
1.08 \\
\end{array}$ \\
\hline \multicolumn{3}{|l|}{ Appraisal of crisis management } \\
\hline \multicolumn{3}{|l|}{ Quality of official information } \\
\hline Below average (negative) & 1.16 & $\begin{array}{c}0.91 \text { to } \\
1.46\end{array}$ \\
\hline Above average (positive) & 0.95 & $\begin{array}{c}\text { to } 0.82 \\
1.02 \\
\end{array}$ \\
\hline \multicolumn{3}{|l|}{$\begin{array}{l}\text { Agreeable to 14-day quarantine after non close contact with (nCoV-2019) infected person } \\
\text { and no symptoms }\end{array}$} \\
\hline Agree & 0.96 & $\begin{array}{l}0.99 \text { to } \\
1.04\end{array}$ \\
\hline Don't agree or Don't know & 1.08 & $\begin{array}{l}\text { to } 0.88 \\
1.32\end{array}$ \\
\hline
\end{tabular}


OR, odds ratio; CI, confidence intervals. ${ }^{*} p, 0.05, * * p, 0.01 ;$ _Odds ratios were adjusted for all other variables in the models.

\section{Figures}

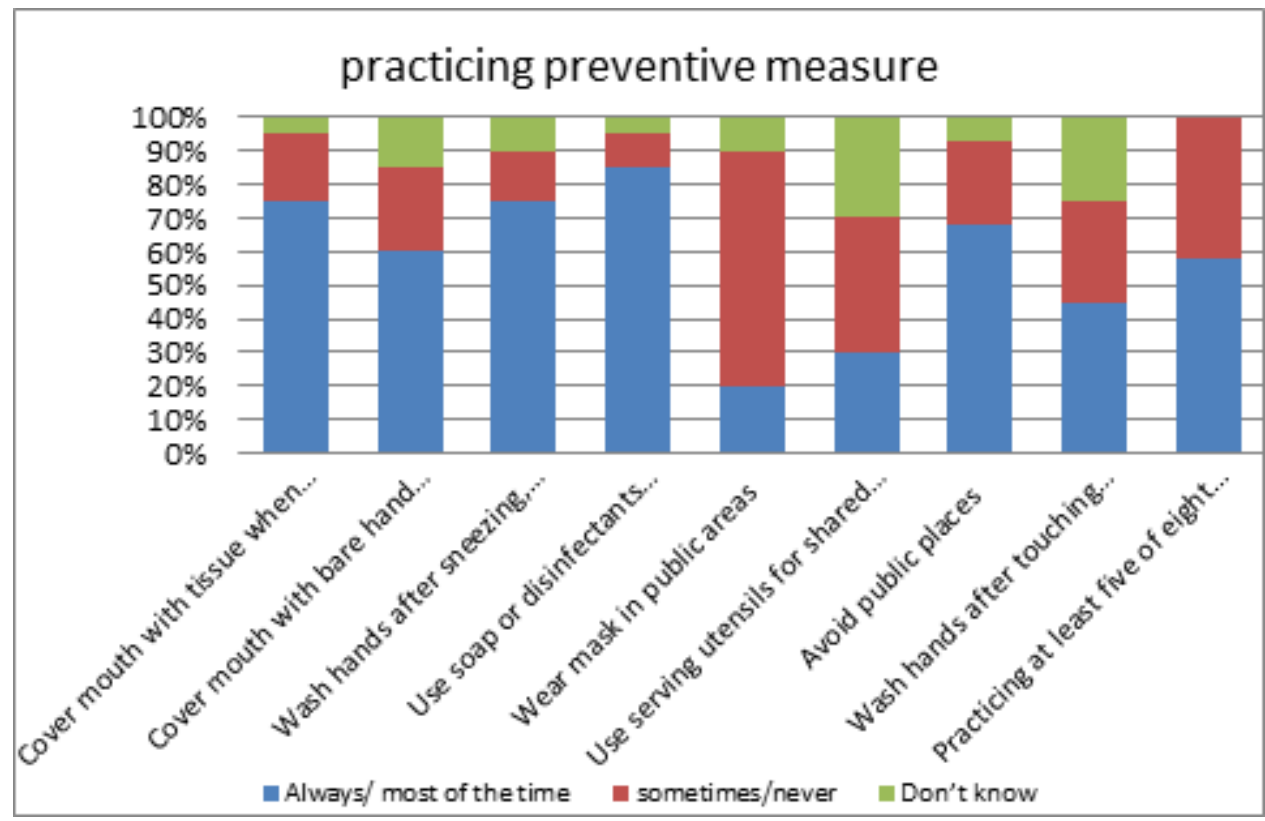

\section{Figure 1}

Practice of preventive measures to prevent transmission and contracting (2019-nCoV).

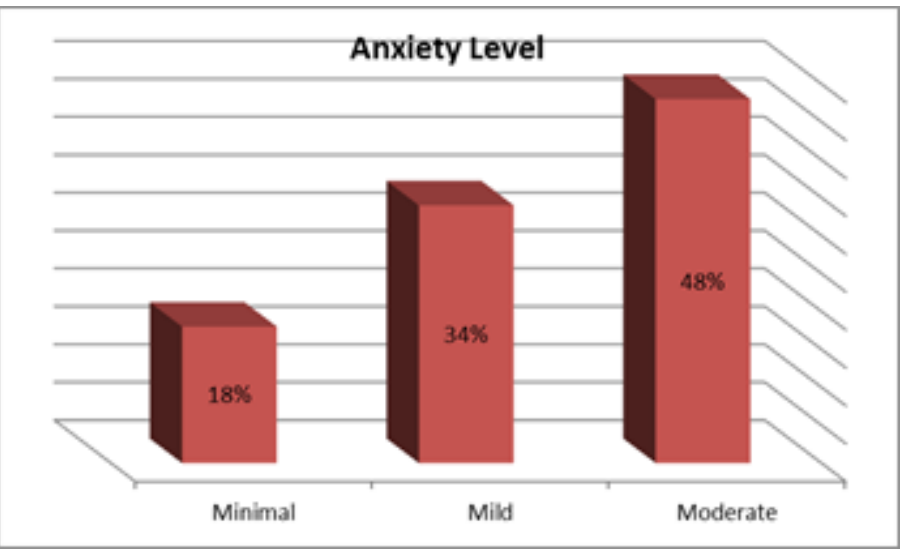

\section{Figure 3}

GAD-7 anxiety level category 


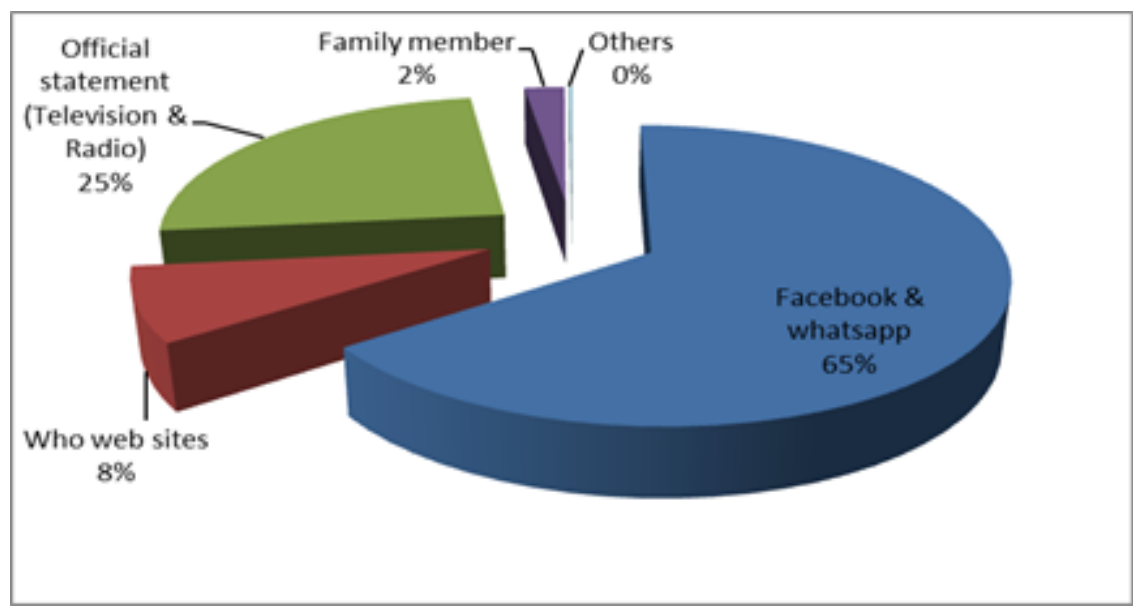

\section{Figure 5}

Information accessed resources

\section{Supplementary Files}

This is a list of supplementary files associated with this preprint. Click to download.

- Suplementarymaterial.pdf

- Suplementarymaterial.pdf 